\title{
Educação Física escolar e dança: percepções de professores no ensino fundamental
}

\author{
Neusa Dendena Kleinubing*
}

Maria do Carmo Saraiva**

\begin{abstract}
Resumo: Este artigo apresenta dados e discussões de uma pesquisa que objetivou compreender a percepção de professores de educação física no ensino fundamental, em relação ao conteúdo dança nas suas aulas. Os dados coletados apontam, especialmente, para questões relacionadas à formação inicial e suas implicações no trato com esse conteúdo na escola. Destacou-se a negligência com o ensino da dança entre os conteúdos da educação física, o que reforça a necessidade de se ampliar e aprofundar as discussões que indiquem um caminho para que a dança realmente se efetive no âmbito escolar.

Palavras-chave: Dança. Educação Física. Ensino fundamental.
\end{abstract}

\section{INTRODUÇÃo}

Percebe-se, na atualidade, um grande número de pesquisadores investigando o fenômeno da dança no contexto da educação, discutindo questões ligadas à legitimidade da dança no campo de Educação Física, bem como as contribuições dessa prática corporal como experiência estética.

O aumento das pesquisas enfocando a dança reflete a importância que essa temática, por muito tempo negligenciada pela escola e pelos professores, vem ganhando. Questões ligadas ao currículo (BRASILEIRO, 2003), ao contexto educacional (MARQUES, 2001, 2005) e à dança enquanto experiência estética (SARAIVA et al., 2005a, 2005b) são alguns exemplos de discussões que buscam investigar esse fenômeno que, apesar de muitos professores não se responsabilizarem pela orientação dessa atividade, insiste em se "fazer presente" na escola.

*Professora da Universidade Comunitária Regional de Chapecó - UNOCHAPECÓ. Chapecó, SC, Brasil. E-mail: neusadk@gmail.com

${ }^{*}$ Professora da Universidade Federal de Santa Catarina - UFSC. Florianópolis, SC, Brasil. E-mail: marcarmo@terra.com.br 
194 Artigos Orifinais Neusa D. Kleinubing e Maria C. Saraiva

Com esta pesquisa, pretende-se contribuir com as discussões acerca da dança e seu papel na escola, apresentando dados coletados em uma pesquisa que buscou identificar a percepção de professores de educação física no ensino fundamental, com relação ao conteúdo da dança nas suas aulas.

\section{MetodologiA: DO CAMINHO E dOS SUJEITOS DA PESQUISA}

É com o objetivo de entender e, sobretudo, lançar questionamentos sobre a dança no currículo da educação física escolar, que foi planejado ouvir as vozes de quem faz acontecer a Educação Física no contexto escolar: o professor e a professora de Educação Física.

A construção da história dessa disciplina na escola se concretiza pela práxis dos professores em relação a seus alunos e em relação ao contexto histórico-social em que essa se efetiva. Portanto, mais do que descrever e situar as ideias dos professores pesquisados, o desafio é perceber as mensagens implícitas, as dimensões contraditórias e os temas silenciados (LÜDKE; ANDRÉ, 1986), mas latentes, nos dados oferecidos pelos atores dessa investigação, buscando entender os textos e os contextos da problemática da dança na escola.

Nesse propósito, desenvolveu-se uma investigação interpretativa, que propõe a compreensão dos significados no âmbito da realidade natural de interações sociais, e cujo foco são os aspectos singulares, imprevistos e diferenciados, conforme Perez Gómez (1998). Essa atitude interpretativa ${ }^{1}$ perante o contexto da pesquisa permitiu-nos mergulhar na complexidade dessa questão que apresenta suas interfaces com a realidade social, emergindo várias análises a partir dos dados coletados.

A pesquisa se configurou a partir do entendimento de que a dança - como elemento da cultura de movimento, fenômeno que em sua gênese apresenta uma riqueza de possibilidades em vivências corporais, sociais e afetivas - tem papel especial na formação humana. Ela possibilita diferentes experiências estéticas que promovem "a ampliação da

${ }^{1}$ Pérez Gómez (1998) aponta esse tipo de pesquisa em oposição ao enfoque positivista que de modo geral busca a generalização abstrata de verdade duradoura independente do contexto.

Movimento, Porto Alegre, v. 15, n. 04, p. 193-214, outubro/dezembro de 2009. 
sensibilidade - como a capacidade de percepção do mundo, tornando capaz de vivenciá-lo, refleti-lo e recriá-lo" (SARAIVA et al, 2005b, p. 61).

Tendo-se consciência desse fato, as inquietações prosseguiram no sentido de explorar e buscar sentidos/significados na práxis do professores de educação física, com a intenção de compreender o presente e poder-se projetar um olhar para o futuro da dança na prática escolar.

Para a coleta dos dados, foi elaborado um questionário semiaberto com perguntas relativas à formação e à prática pedagógica dos professores. Primeiramente, esse instrumento de pesquisa passou por um estudo piloto para que se pudesse avaliar o alcance das perguntas em relação ao seu objetivo. Em seguida, algumas dessas questões foram reestruturadas e, só então, iniciou-se a coleta de dados junto aos sujeitos da pesquisa.

O campo de pesquisa configurou-se a partir da intenção de obter uma amostra que pudesse de alguma forma representar as diferentes realidades das escolas municipais. Assim, foram elencadas 7 escolas das quais 2 são consideradas de grande porte (de 700 a 1.000 alunos), 2 de médio porte (de 300 a 700 alunos) e 3 consideradas de pequeno porte (de 90 a 300 alunos). Esses dados foram disponibilizados pela secretaria de educação do município.

A pesquisa envolveu todos os professores de educação física dessas escolas totalizando 16 professores: 7 homens e 9 mulheres. Desses, 3 apresentaram idades entre 18 e 27 anos, 11 entre 28 e 37 anos e 02 entre 38 e 47 anos. Todos residem no município de Chapecó, em Santa Catarina.

Quanto ao nível escolar em que atuam os pesquisados estendemse desde a Educação Infantil até as séries finais do Ensino Fundamental, compreendendo 7 professores que atuam na educação infantil e séries iniciais ( $1^{\mathrm{a}}$ a $4^{\mathrm{a}}$ séries), 5 professores lecionam para alunos das séries entre $5^{\mathrm{a}}$ e $8^{\mathrm{a}}$ do ensino fundamental, e outros 4 que atuam em todos esses níveis.

O próximo item envolveu a relação dos pesquisados com a disciplina dança no período da formação inicial. Entre os professores, 11

Movimento, Porto Alegre, v. 15, n. 04, p. 193-214, outubro/dezembro de 2009. 
assinalaram que tiveram a disciplina dança inserida no currículo do seu curso de graduação e, destes, 9 afirmaram que os conteúdos vivenciados na formação foram significativos. Apenas 2 consideraram que essa disciplina não foi trabalhada significativamente nas suas graduações. Os outros 5 informaram que não tiveram a dança, mas sim, outras disciplinas de conteúdos aproximados que continham alguns elementos relacionados, tais como: Atividades Rítmicas, Ginástica Rítmica e Folclore.

As questões seguintes do questionário envolveram a problemática central da pesquisa, o conteúdo dança na disciplina da educação física escolar, e buscaram visualizar a realidade desse conteúdo na escola e a relação do professor com a dança no seu ensino. Nisso, 11 professores responderam que desenvolvem a dança, mas não de forma sistemática. Esses professores relatam que a desenvolvem normalmente quando há algum evento ou data comemorativa. Os outros 5 professores informaram que trabalham a dança nas suas aulas de educação física.

Esses primeiros dados caracterizaram o grupo de professores, localizando-os no cenário da investigação, e tendo as referências sobre a sua formação relacionada à dança, partiu-se para o propósito de analisar as respostas desses professores, buscando suas divergências e suas ideias em comum. Tentou-se, também, perceber as entrelinhas desses dados, aqui formatados em falas escritas, almejando fazer o exercício que Freire (1996) ensinou, pois, afinal, o espaço pedagógico e a prática pedagógica são textos para serem constantemente lidos, interpretados, escritos e reescritos.

\section{A DANÇA NA ESCOLA: TENSÕES ENTRE VIVÊNCIA E FORMAÇÃO}

No processo de análise dos dados, surgiram vários elementos significativos para a compreensão do problema e, neste texto, apresentase a questão central destacada das respostas dos professores: a implicação da formação inicial.

Vários professores pesquisados afirmaram que tiveram a Dança no seu currículo de Educação Física, mas que os conteúdos dessa dis-

Movimento, Porto Alegre, v. 15, n. 04, p. 193-214, outubro/dezembro de 2009. 
ciplina não forma significativos para eles, o que levou à necessidade de entender o porquê. Segundo algumas respostas, para esses professores os conteúdos não foram significativos porque o contato com a dança "somente em um período da graduação foi muito corrido" (Professora M), e também porque "poderiam ter ampliado mais, para melhor aproveitamento nas escolas" (Professora E).

Essas evidências se aproximam dos resultados de pesquisa realizada por Saraiva et al. (2007), na qual os professores também apontam a falta de vivência em dança, tanto na vida pessoal como na formação inicial, como elemento limitador para desenvolverem esse conteúdo nas suas aulas. Entretanto, alguns professores desta pesquisa informaram que os conteúdos trabalhados na disciplina de Dança na graduação foram significativos e, em alguns casos, "foi bastante trabalhado a questão da expressão corporal" (Professora A).

Em relação aos conteúdos tratados na disciplina de dança nos cursos de Educação Física cabem algumas considerações. Primeiramente, entende-se que a organização curricular dos cursos de Educação Física não possibilita o aprofundamento de técnicas específicas de estilos de dança, bem como, entende-se que esse não deve ser o objetivo da formação. Todavia, há possibilidades, como já demonstrado em outros estudos, a partir das perspectivas da Dança-educação ou Dança-improvisação ${ }^{2}$, da dança ser entendida como experiência, na qual "outra forma de vida se revela em movimento", conforme Saraiva (2005, p. 239), configurando como outra forma de ser e estar no mundo, que é simbolização do vivido e/ou imaginado, possível a todas as pessoas.

Nesse sentido, a experiência $n a$ e $d a$ dança deve ser compreendida como possibilidade de representação das experiências vividas: um processo relacional do corpo em movimento que constituindo o fenômeno da dança, deve ser perspectivado como um modo diferente, ou seja, como outra forma de vivenciar e se apresentar no mundo. Esse pensamento traz a ideia de que ao experienciar a dança somos capazes de expressar, de modos singulares, o entendimento que temos do mundo que nos cerca, bem como somos capazes de expressar nos-

${ }^{2}$ Ver Fiamoncini e Saraiva (1998), Soares et al. (1998), etc.

Movimento, Porto Alegre, v. 15, n. 04, p. 193-214, outubro/dezembro de 2009. 
sas emoções e sentimentos sem, necessariamente, dominarmos uma técnica específica de dança. Assim, contemplamos a dança a ser discutida e trabalhada no âmbito da educação, e em especial da educação física, como aquela que possibilita aos sujeitos apresentarem seus pontos de vistas com relação a seus mundos construídos a partir das suas experiências, já que "a relação de cada pessoa com a dança é algo diferenciada conforme sua vivência subjetiva e a realidade social" (SARAIVA, 2005, p. 232).

Nessa perspectiva, a formação dos professores deve ser objetivada a partir de conceitos e entendimentos de dança que compreendam a experiência estética como eixo central do processo, pois nela radica o desenvolvimento da sensibilidade, que pode desbloquear potencialidades do ser humano. Esse tipo de experiência desenvolve a "consciência estética que não é prerrogativa dos artistas, mas de todos que ousem novas possibilidades" (SARAIVA-KUNZ, 2003, p. 71).

A dança concebida nessa dimensão poderia diminuir a sensação de incapacidade dos professores de educação física para trabalhar com a dança nas suas aulas. Afirmativas como "não possuir conhecimento e vivência suficiente para desafiar-me a trabalhar de forma eficiente a dança" (Professor L), e "não estar preparado suficiente para conduzir as aulas" (Professor I), seriam menos frequentes, se pudéssemos perceber no corpo próprio a capacidade expressiva, representante da faticidade humana, que integra tanto a estrutura do sujeito quanto a estrutura do mundo. Essa concretude é passível de ser redimensionada pela experiência da dança.

Além da falta de capacitação na formação inicial, repetidamente expressa pelos professores, também é apontado "o enorme desinteresse dos professores em querer aprenderem e trabalhar a dança" (Professor P). Essa afirmação aponta para um fator que, entende-se, ser um dos maiores obstáculos na tentativa da dança ganhar espaço e corpo nas escolas. Pode-se ver isso pelo viés da formação permanente. Como vários professores apontaram não terem recebido formação suficiente na graduação, é fundamental buscar conhecimentos além dos recebidos na licenciatura, através de cursos, pesquisas ou livros. E isto vale não somente para a dança, mas para qualquer conteúdo e/ou disciplina. A produção de conhecimento em nossos tempos ultrapassa 
a de qualquer outra época da história e a disseminação desse conhecimento, também, é de forma acelerada. Então, o conhecimento que nos falta é passível de ser sanado, se não totalmente, pelo menos em parte, a partir da formação permanente, que pode ser entendida como participação em cursos de aperfeiçoamento e, até mesmo, como atitude de autodidatismo. Outros estudos também apontam para a falta de interesse dos professores como um dos fatores responsáveis pela negligência para com o ensino da dança nas escolas. No estudo de Saraiva et al. (2007a, p. 152), é mencionado que:

[...] as/os professoras/es reconheceram que a dança tem sido negligenciada nas unidades educativas e os motivos levantados [...] foram: a falta ou precariedade de experiências e vivências práticas em dança, na vida pessoal e na formação inicial (faculdade) e a falta de vontade, como desmotivador principal de um trabalho mais efetivo em dança nas escolas.

Todavia, dados desta pesquisa apontam muito mais para uma posição efetiva de não afinidade com a dança, ou de não se sentirem à vontade em desenvolver esse conteúdo, como bem expressa esta fala: "não possuo uma afinidade pela dança como tenho para os esportes de quadra" (Professor O). Da mesma forma, algumas das justificativas mais incisivas para não ensinar a dança nas aulas de educação física foram: "por falta de domínio do conhecimento sobre a dança e a expressão corporal" (Professora F), ou "por não ter muito conhecimento" (Professor I) e, também, "por que não gosto e por não ter o jeito para trabalhar com a dança" (Professor P).

Incisivas, diz-se das respostas, porque os professores de certa forma se abstêm de duas condições fundamentais da prática educativa que busca a dignidade da condição humana, manifestando um aparente conformismo. A primeira é representada pela vontade de ampliar os conhecimentos, que leva a busca da formação permanente, tão importante e decisiva para a prática pedagógica do professor. Esta deve firmar-se como eterna ação-reflexão-ação, o fazer e o pensar sobre o fazer, como proferiu Freire (1996), entendendo esse movimento como necessidade básica para uma prática docente crítica. Nessa situação, o/a professor/a adquire uma postura investigativa frente às diferentes situações advindas do processo pedagógico, tomando consciên-

Movimento, Porto Alegre, v. 15, n. 04, p. 193-214, outubro/dezembro de 2009. 
cia de que não há ensino sem pesquisa, nem pesquisa sem ensino (FREIRE, 1996).

A segunda questão é caracterizada pela oferta necessária, no caso da educação física, de um amplo campo de vivências das práticas corporais da contemporaneidade. Um olhar mais atento vai identificar que, na atualidade, as práticas corporais ultrapassam a linha do campo dos esportes. Atividades ligadas à natureza, às artes marciais, voltadas ao cuidado com a saúde, somente para citar alguns exemplos, exigem um novo olhar do professor de educação física, buscando compreender esse movimento, que de modo geral, objetiva (re)integrar o ser humano com sua natureza biológica e cultural, individual e coletiva. É importante salientar o compromisso da educação física com atividades que contribuam para a formação dos sujeitos. Essa contribuição, necessariamente, passa pela ampliação das práticas corporais, pois somente com práticas corporais próprias, que sejam autênticas para o sujeito que as realiza, descobre e constrói, é que esse poderá perceber-se uma totalidade, exigindo constantemente um processo de ressignificação de seus movimentos a partir do contexto em que se inserem. Entende-se que o repertório de movimento do sujeito traz consigo as novas linguagens corporais polissêmicas, que decorrem do ambiente natural e social, que lhes confere inúmeros significados, com o que "o ambiente, mesmo, também vai sendo reconstruído a partir da experiência e por meio do compartilhamento, assumindo novos sentidos" (SILVA; DAMIANI, 2005, p. 195).

Esse entendimento faz compreender a importância de oferecer experiências com práticas corporais - e aqui se olha de modo especial para a dança-que aumentem o repertório de movimento dos sujeitos, ampliando o diálogo com o corpo próprio e com o corpo do outro, aprofundando o conhecimento do mundo do qual faz parte. É nesse sentido que, no caso da dança, alguns professores e professoras não devem sobrepor uma atitude pessoal negativa às possibilidades de um coletivo.

É importante ressaltar que as afirmações sobre não ensinar a dança por "falta de afinidade", ou seja, não gostar, ou por "não ter jeito" foram apresentadas por professores do sexo masculino. Talvez esse seja um indício do forte preconceito que ainda cerca a dança,

Movimento, Porto Alegre, v. 15, n. 04, p. 193-214, outubro/dezembro de 2009. 
no que diz respeito à participação dos homens, já que a história da dança tem apontado que muitos bailarinos foram e/ou são homossexuais (HANNA, 1999). Todavia, a análise de aspectos como a homossexualidade no âmbito da dança não é foco deste texto, mas sim, refletir sobre o fenômeno que concretiza a dança, o que dá visibilidade a essa linguagem: o movimento humano.

A dança se concretiza através da transformação/ressignificação do movimento humano, e esse, sem dúvida, é assexuado. Tanto o homem quanto a mulher utilizam os mesmos grupos musculares no movimento do andar, correr, saltar, nadar e também dançar, e a distinção entre o movimento, em ambos os sexos, tanto pode depender "da emoção que cada um imprime à sua expressão" (NANNI, 1995, p. 130), como dos "impasses identificatórios nas práticas corporais", como detectou Fraga (1995). Numa investigação com adolescentes que foram submetidos à análise comparativa as práticas de futebol e da dança, e $o$ autor encontrou que

[...] o poder preponderantemente masculino reconhecido nesse jogo por seu temperamento agressivo, viril e competitivo passou a diluir-se entre os sexos com o transcorrer das atividades escolares, abrandando tais características nos meninos e salientando-as nas meninas com relativa freqüência (FRAGA, 1995, p. 38).

Da mesma forma, relata o autor, "a angústia dos rapazes diminuía na mesma proporção em que se sentiam mais identificados com seu papel na dança" (FRAGA, 1995, p. 39), já que se tratava de encenar a dance music, uma dança que sofreu um processo de dessexualização, na década de oitenta, tal como hoje acontece com o street dance ou dança de rua.

De qualquer forma, vemos que, em estudos que já datam de mais de uma década, apresentam-se possibilidades de reinterpretação dos papeis de gênero na dança e, sobretudo, de ressignificação da dança para meninos e meninas, já que:

em qualquer cultura, nenhuma prática corporal
enseja em si mesma as noções substantivas de sexo-
gênero, não só porque há transformações a partir de
uma dinâmica cultural, dentro de uma mesma socie-

Movimento, Porto Alegre, v. 15, n. 04, p. 193-214, outubro/dezembro de 2009. 
dade, mas porque tais transformações nos remetem a uma dimensão semântica que está contida no processo de configuração de identidades sociais, mesmo aquelas que se fundam em papeis sexuais (FRAGA, 1995, p. 40-41).

Desse modo, acredita-se que o preconceito se associa à ideia de que a criatividade e a sensibilidade são "habilidades" ligadas ao universo feminino, pensamento disseminado pela sociedade moderna e, portanto, a referência ou o imaginário da figura do homem na dança é uma construção histórico-social na qual a lógica difundida de que o homem que dança é homossexual, ainda que infundada, infelizmente, flui no universo masculino. Desde o trabalho de Leitão e Sousa (1995) sobre $\mathrm{O}$ homem que dança..., tal como desde as interpretações clássicas ocidentais do que "é apropriado para o homem", nomeando, eufemisticamente, tudo que "não é apropriado" como atributos dos homossexuais (BURT, 1995), até os dias de hoje, vemos a dança ser interpretada como "emocionalmente" expressiva, um atributo feminino, no senso comum. Conforme Burt (1995) algumas emoções são associadas com a masculinidade, enquanto outras parecem ser femininas, de forma que os homens dizem, frequentemente, ser mais racionais e ter mais controle de suas emoções que as mulheres.

Entretanto, deve-se pontuar que alguns professores, de certa forma, sentiam necessidade de aprofundar ou ampliar seus conhecimentos referentes à dança: "sinto necessidade de maiores conhecimentos para aprimorar minha prática pedagógica educacional, haveria crescimento profissional" (Professor J) e, "gostaria de trabalhar dança, mas não só por trabalhar" (Professor I). Nessas falas, percebe-se, também, além do déficit em relação aos conteúdos de dança, uma certa crítica, pois quando o professor afirma "não só por trabalhar" refere-se, possivelmente, ao fato da dança, frequentemente, ser fruto do livre fazer "das alunas"', sem orientação do/a professor/a. Assim, percebe-se nessa fala o sentimento de necessidade de saber o que se está dançando e não somente dançar uma música qualquer.

${ }^{3}$ Normalmente, quando acontecem mostras de dança ou algum evento na escola, "as meninas" tomam a iniciativa organizando as coreografias para as apresentações.

Movimento, Porto Alegre, v. 15, n. 04, p. 193-214, outubro/dezembro de 2009. 
Nessa perspectiva, experiências têm confirmado a formação permanente como uma possibilidade real de aproximação de educadores com o universo da dança, mostrando que o/a professor/a, a partir da vivência efetiva da dança, é capaz de

perceber e compreender, também, como o movimento torna-se experiência corpórea para seus alunos, ou seja, torna possível compreender as possibilidades, dificuldades e anseios presentes na execução das tarefas, ao virem a ser utilizadas na prática pedagógica (SARAIVA, 2007a, p. 154-155).

\section{Meninos nÃo dançAM! NÃo temOS ESPAÇO! É PRECISO SUPERAR ESSES OBSTÁCULOS}

Os professores pesquisados destacaram a não participação dos meninos nas atividades de dança. Para alguns professores, um dos obstáculos para a implementação da dança nas aulas de educação física é a "resistência por parte de alguns, principalmente meninos" (professor $\mathrm{H}$ e professora $\mathrm{J}$ ).

A carência de outras referências de estilo de dança, para além das imagens do ballet, ainda bastante impregnadas no imaginário social como a dança, apesar das novas influências, especialmente de hip hop, dança de rua, forró etc., mais fortes em grandes centros urbanos, ajuda a reforçar o estereótipo sobre o menino-bailarino. $\mathrm{O}$ que nos parece mais estimulador para iniciar os meninos na dança e que alguns estudos já apontaram (ARNOV, s/d; FRAGA, 1995; STINSON, 1998) é transportar os movimentos corporais do universo do esporte para a dança. Esses movimentos exigem força, vigor e podem ser uma estratégia utilizada pelo/a professor/a com o objetivo de proporcionar o primeiro contato com essa linguagem corporal. Stinson (1998a, p. 60) comenta sua estratégia de aula:

frequentemente inicio as aulas para crianças de 10 anos em diante com atividades que envolvam a relação entre dança e esporte [...] é possível perceber a surpresa dos meninos quando descobrem que gostam de dançar, pelo menos, esse tipo de dança.

Movimento, Porto Alegre, v. 15, n. 04, p. 193-214, outubro/dezembro de 2009. 


\section{Artigos Orifinais Neusa D. Kleinubing e Maria C. Saraiva}

Também no sentido de viabilizar a dança de uma forma não intimidadora para os meninos, a autora, em outro trabalho, afirma ser "necessário, embora não suficiente, começar cedo, e ensinar dança de uma forma agradável para os meninos e que não seja ameaçadora de sua masculinidade" (STINSON, 1998b, p. 68). Isso é possível acreditando-se que a vivência da dança, já na idade pré-escolar, possibilita a ampliação das referências e experiências corporais, além de auxiliar no entendimento de que essa atividade é compatível para ambos os sexos, já que a dança "tem um papel significativo nas construções infantis dos estereótipos masculino e feminino" (BOND, 1998, p. 50).

Em interessante trabalho, Bond (1998, p. 52) observou um grupo de crianças utilizando máscaras para desempenhar seus papéis de dançarinos. A autora revela que o uso dessas possibilitou "afastar temporariamente as inibições ligadas ao gênero e trazer à tona um senso aumentado de individualidade." Essa pode ser outra estratégia a ser utilizada com o intuito de aproximar os meninos do universo da dança, bem como possibilitar-lhes a dança de rua, que foi largamente difundida em nossa cultura nos anos 90. Esse estilo de dança explora habilidades como saltos, quedas, torções, grandes giros, movimentos rápidos e coordenados. Todos os movimentos que podem aproximar a dança do esporte, como também, a redescoberta da capoeira que possibilita ser vista como jogo ou dança, igualmente rica em movimentos atléticos e uma manifestação cultural genuinamente brasileira.

Sem dúvida, as referências que se tem de dança são fundamentais na opção de querer/gostar de realizá-la ou não. Por isso, esse viés pode ser um primeiro caminho para que os meninos se sintam estimulados a dançar e, a partir da primeira experiência, percebendo que não "deixaram de ser meninos", possam se permitir experimentar as diferentes possibilidades, diminuindo o "desinteresse e inibição da maioria dos meninos para a dança" (Professor O).

Outra dificuldade para desenvolver a dança na escola, apontada pelos professores, foi a falta de espaço adequado para a realização das aulas. Essa falta de estrutura foi destacada como obstáculo para a concretização da dança:

somos três professores com três turmas ao mesmo tempo na quadra. Falta sala livre para utilizar, deste

Movimento, Porto Alegre, v. 15, n. 04, p. 193-214, outubro/dezembro de 2009. 
modo só é realizada dança para apresentações em datas comemorativas, e não como conteúdo fixo (Professora K);

"falta espaço adequado onde a intensidade do som possa ser maior, bem como, uma sala com tamanho adequado para a movimentação" (Professor O). Nestas duas falas têm-se a representação da imagem de uma estrutura ideal para o desenvolvimento da dança. Todos sabem das condições precárias da maioria das escolas públicas desse país, todavia, mesmo as quadras não tendo condições ideais também para a prática dos esportes, estes não deixam de ser trabalhados nas aulas de educação física.

É necessário, sim, “pensarmos o espaço físico como um desafio constante para professores que pensam uma Educação Física que amplia suas referências de conhecimento" (BRASILEIRO, 2002, p. 9), mas a experiência da/com a dança em espaços não convencionais - a clássica sala com piso de madeira, barras e espelho - já foi apontada por diversos autores e, efetivamente, realizada por diferentes artistas/ dançarinos ao longo da história. Saraiva et al. (2005b) relatam diferentes espaços nos quais a dança pode ser experienciada. Quadras e bosque transformam-se em cenários que fazem surgir diferentes questionamentos em relação à necessidade de um espaço "ideal" para a dança. Essa reflexão pode ajudar na hora de planejar e organizar a dança compreendendo os espaços disponíveis da escola.

\section{DA UTILIDADE À LEGÍTIMA FORMA DE EXPRESSÃO}

Outro ponto importante da pesquisa foi a busca de desvelamento das possíveis contribuições do trabalho com a dança para o processo educativo. Dois aspectos foram bastante ressaltados pelos professores pesquisados: a dança como instrumento para o processo de sociabilização e como facilitadora do desenvolvimento motor.

Para os professores perguntados, a dança "contribui na socialização, no desenvolvimento rítmico, percepção espaço-temporal, concentração, valências físicas e na desinibição" (Professor I); além dessas habilidades, para a "flexibilidade, agilidade, resistência e coordenação

Movimento, Porto Alegre, v. 15, n. 04, p. 193-214, outubro/dezembro de 2009. 
motora” (Professor J); e, também, “contribui para a coordenação motora de membros inferiores e superiores" (Professor O).

Essas ideias representam as formas utilitárias frequentemente atribuídas à dança e usadas como justificativas para defender sua presença em qualquer programa/currículo. Ainda é difícil entendê-la como uma forma de expressão, ou como outra forma de experimentar e falar das coisas que fazem parte do nosso mundo. Embasados por uma formação tecnicista, os professores tem percebido com mais facilidade as habilidades físicas e capacidades motoras na dança, do que o seu potencial expressivo e comunicativo. Perceber o movimento de dança como forma de potencializar ou render mais em uma ou diversas habilidades motoras é uma maneira reduzida de compreender esse conteúdo, bem como a própria educação física. As habilidades e capacidades devem ser consideradas, mas não podem ser objetivos únicos da proposição de atividades pedagógicas, pois desse modo o professor passa a ser "um educador com muito pouco de formador, com muito mais de treinador, de transferidor de saberes, de exercitador de destrezas" (FREIRE, 1996, p. 162, grifo do autor).

Essa condição é realmente insuficiente se idealizada uma educação física crítica e emancipatória. Essa perspectiva compreende o sujeito em movimento, ou o sujeito no seu se-movimentar, caracterizado pelas "relações de sentido/significado entre ser humano e mundo que se estabelecem pelo movimentar-se, como uma experiência estética" (KUNZ, 2006, p. 20). Não se nega características intrínsecas do movimento em dança (flexibilidade, coordenação, orientação espaço-temporal, etc.), que devem ser trabalhadas como meios para a possibilidade de expressão, contudo, entende-se que deve ser focalizado o objetivo principal, que é a experiência do corpo em movimento, voltada para o exercício da criação e colaborando para o conhecimento de si. Esse conhecimento, quando aprofundado, "permite uma consciência também alargada de mundo e de nós mesmos" (KUNZ, 2001, p. 51) e, assim, compreendemos que o sujeito em movimento entende-se com seu mundo e nesse diálogo pode se (re)conhecer como sujeito capaz de atitudes de interferência no mundo.

A dança como outra forma de linguagem e como possibilidade de diálogo com o mundo e com o outro pode ser identificada em respostas

Movimento, Porto Alegre, v. 15, n. 04, p. 193-214, outubro/dezembro de 2009. 
como: "a dança proporciona uma forma diferente de exteriorizar sentimentos" (Professor L), ou que a dança contribui

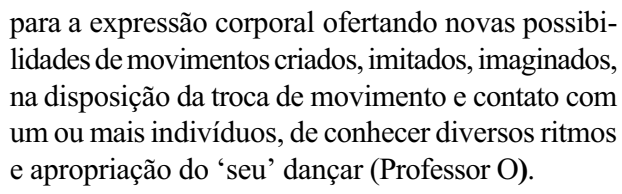

Esses entendimentos se aproximam do que se acredita ser a proposta da dança no contexto escolar: uma forma diferenciada de falar sobre as coisas que nos constituem, uma outra possibilidade de nos apresentar no e para o mundo, uma experiência que permita nos encontrar e encontrarmos o outro a partir das múltiplas formas de se-movimentar.

\section{DANÇA PROFESSOR de EdUCAÇÃo FísICA: ENSAIO PARA UMA APROXIMAÇÃO}

A capacidade de sensibilização e organização das pessoas que compartilham a experiência da dança, a experiência de serem corpos dançantes, faz com que essas se voltem para suas condições de sujeitos que estão no mundo, constituídos e constituintes das suas histórias. Nisso, a dança é

como uma forma de expressão da cultura corporal, sendo que o resgate das possibilidades de expressão é importante para a tomada de consciência de nossa situação no mundo e para a busca da singularidade (individualidade) (SOARES; SARAIVA, 1999, p. 105).

Se a cultura corporal é a "denominação dada ao amplo e riquíssimo campo da cultura que abrange a produção de práticas expressivocomunicativas, essencialmente subjetivas, externalizadas pela expressão corporal" (ESCOBAR, 1999, p. 91), e a dança uma forma de expressão da cultura corporal - como resultado de conhecimento produzido e acumulado em relação ao corpo - não pode, então, ser negligenciada como conteúdo da educação física escolar.

$\mathrm{Na}$ análise dos textos dos professores sujeitos da pesquisa ficou claro que a dança é um conteúdo pouco explorado nas aulas de educação física por diversos motivos. Os mais evidenciados foram a falta de

Movimento, Porto Alegre, v. 15, n. 04, p. 193-214, outubro/dezembro de 2009. 
conhecimento em relação à técnica da dança e a pouca afinidade com esse conteúdo. Assim, a dança, como todos os outros conteúdos da Educação Física escolar, precisa ser trabalhada na perspectiva da superação da concepção técnica e de instrução; precisa ser percebida como uma forma de vivência das atividades libertadoras, das atividades criativas, que possam levar os alunos (e professores) a uma mudança de atitude perante a realidade excludente e cruel que se apresenta a toda a humanidade.

Como afirma Kunz (1999, p. 66)

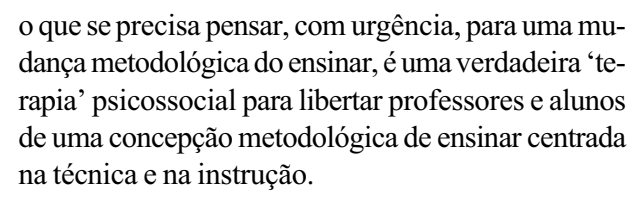
dança metodológica do ensinar, é uma verdadeira 'terapia' psicossocial para libertar professores e alunos de uma concepção metodológica de ensinar centrada na técnica e na instrução.

Acredita-se na força dos movimentos que surgem dos corpos e não nos movimentos impostos aos corpos, enquadrados num jeito "técnico e certo" de fazer, pois é dever do/a educador/a ver, ouvir e perceber seus alunos na sua integralidade. No momento em que o/a aluno/a cria e expressa um movimento, ou até mesmo, um "não movimento", precisa-se estar atento a ele, sua história, pois suas marcas estão ali, presentes, se fazendo num sujeito concreto. Nesse sentido, a dança pode ser uma forma libertadora para a expressão dos corpos, pois o movimento de dança "é o espaço exterior da imaginação, que esse movimento libera sentimentos e emoções, além de refletir e expressar as transformações do ser no todo" (FIAMONCINI; SARAIVA, 1998, p. 96).

Assim, a preocupação deve se fixar nas oportunidades que se deixa de oferecer aos alunos quando elegidas algumas poucas práticas corporais na concretização da educação física, contribuindo para a cristalização de conceitos e falsas verdades, como a de que essa disciplina se sustenta a partir de duas ou três modalidades esportivas. $\mathrm{O}$ professor de educação física precisa saber que pertence aos interesses objetivos dos alunos "a possibilidade de conhecer e interagir com todas as diferentes manifestações da cultura do movimento possível de serem desenvolvidas numa aula de Educação Física" (KUNZ, 1999, p. 67).

Movimento, Porto Alegre, v. 15, n. 04, p. 193-214, outubro/dezembro de 2009. 
Contrapondo-se a esse entendimento, alguns professores demonstraram não ter interesse em aprofundar seus conhecimentos com relação à dança, por diversos motivos como estar seu interesse "direcionando a educação física na escola para todas as áreas do esporte $\mathrm{e}$ a dança requerer um tempo maior, espaço adequado" (Professora B), e "direcionando os estudos e aprofundamentos na área do rendimento" (Professor C).

Compreendido é que, para esses professores, a dança não é vista como um conteúdo da educação física escolar. Também ficou claro qual o entendimento de educação física ainda presente na escola, uma atividade voltada quase que exclusivamente para o desenvolvimento dos esportes competitivos ficando, frequentemente, restrita aos esportes mais populares: futebol, voleibol, handebol e, quando há estrutura, o basquete.

No entanto, é importante salientar que houve um reconhecimento de que a dança contribui no processo educativo, mesmo pelos que declararam não trabalhar e/ou não ter interesse em ampliar seus conhecimentos nesse conteúdo. Pelo viés da práxis, esses dados apontam para uma contradição: mesmo o professor tendo o conhecimento de que o conteúdo dança é um elemento importante para o desenvolvimento do aluno, não lhe possibilita a vivência.

Como já salientado, estudos apontam para a importância da formação permanente no fortalecimento da dança na escola e reafirmam a necessidade de uma constante busca sobre os conhecimentos da dança que possibilitam, a partir da vivência própria, "maior amplitude de conhecimento em relação ao trato metodológico da dança na escola" (SARAIVA et al., 2007b, p. 125).

Certamente que há um longo caminho a ser percorrido em relação à efetivação da dança no contexto da educação física escolar, pois ainda falta aos professores entendimento e reconhecimento da importância desse conteúdo nas perspectivas de emancipação dos sujeitos. Entende-se que a dança que deve estar presente nas aulas de educação física é espaço de promoção da criatividade e principalmente, da sensibilidade, pautada nas possibilidades de ouvir, ver, e apreciar o que outros corpos têm a comunicar e expressar. Nessa perspectiva, a dança se apresenta como espaço-tempo em que se pode realizar o difícil

Movimento, Porto Alegre, v. 15, n. 04, p. 193-214, outubro/dezembro de 2009. 
exercício da tolerância, aceitando e reconhecendo o outro como parte fundamental para o nosso próprio processo de formação.

Nesse sentido, a dança na educação física, deve ser trabalhada a partir do histórico de movimento de cada aluno/a e, por isso, nessa proposta, o/a professor/a não precisa ser um/a bailarino/a, pois cabe a ele/a mediar os diálogos e orientar as tarefas de movimento. Nesse processo, a principal "habilidade" a ser "desenvolvida" pelo professor de educação física é a sensibilidade (cabe dizer, não serve somente para a dança): é preciso ser/estar sensível às necessidades de comunicação dos/as alunos/as, ser/estar sensível às necessidades de serem ouvidos, questionados, elogiados e compreendidos.

É necessário fazer-se um esforço para que a dança ocupe seu lugar de direito na disciplina de educação física na escola, pois se trata da experiência própria do se-movimentar, com todas as implicações manifestas desse fenômeno.

\section{CONSIDERAÇÕES FINAIS E... PASSOS INICIAIS}

Retomando as questões que guiaram essa pesquisa pode-se compreender que ainda há muita resistência quanto à prática da dança nas aulas. Isso é justificado por diferentes motivos, sendo a falta de conhecimento referente a esse conteúdo, o mais evidenciado. É importante ressaltar que na matriz curricular dos cursos de graduação em Educação Física há outras disciplinas que são ministradas também, em um ou dois semestres - como alguns esportes - e nem por isso são deixadas de serem ministradas no contexto escolar.

Assim, é possível perguntar: por que esse assunto precisa constantemente ser discutido? A resposta pode ser a notória negligência em relação à dança como conteúdo da educação física escolar, o que reforça a ideia da necessidade de se ampliar e aprofundar essas discussões a fim de visualizar um caminho para que a dança realmente se efetive no âmbito escolar.

As principais ideias defendidas nesse texto apontam a dança como experiência estética (SARAIVA; KUNZ, 2003). Essa compreensão amplia as possibilidades de trabalho e ajuda a evitar-se o equívoco de 
ensinar a dança sem uma orientação pedagógica, e chama a atenção para os modismos impostos pela mídia, que "massificam" as referências do que podemos chamar de dança.

Ultrapassar esses entendimentos faz parte do exercício educativo que compreende, também, a autocrítica. Para desenvolver a dança nessa perspectiva, o/a professor/a de educação física não precisa ser um/a exímio/a bailarino/a ou ser um/a especialista em dança. É necessário que tenha sensibilidade para mediar e direcionar o trabalho, no qual ele/a próprio/a pode (e deve) estar vivenciando a experiência da descoberta, da criação do movimento, atribuindo-lhe um significado, um sentido que é a expressão da sua corporeidade. Deixar de oportunizar aos alunos a experiência da dança é deixar uma lacuna tanto no seu processo educativo quanto no seu desenvolvimento pessoal.

A conclusão transitória desta pesquisa é de que há necessidade de avançar muito no papel de educador-pesquisador. Precisa-se aprender a conviver e a trabalhar com a insegurança, já que, na realidade atual, pretender as certezas é bastante utópico, pois o que era certeza ontem, começa a se fazer dúvida hoje. Nesse sentido, necessita-se desafiar-se continuamente para superar obstáculos e dificuldades; para que estas, "com criatividade e persistência tornem-se oportunidades" (Professora N).

Possivelmente, um dos pontos relevantes desta investigação foi proporcionar ao professor participante um momento de reflexão quanto ao trabalho com a dança na escola. Quer-se acreditar que esse estudo possa ter sensibilizado os professores no sentido de promover um autoquestionamento e, talvez, relembrá-los desse conteúdo como capaz de enriquecer a experiência corporal dos alunos, abrindo novos espaços de comunicação, possibilitando novas formas de linguagens com os outros e com o mundo. Enfim, é a esperança de ver esse conteúdo ganhar corpo e "os corpos na/da escola". 


\title{
212 Artigos Orifinais Neusa D. Kleinubing e Maria C. Saraiva
}

\begin{abstract}
Physical Education and Dance: perception of teachers in elementary school

Abstract: This article presents data and discussions of a research that aimed to understand the perception of physical education teachers in relation to the subject dance in physical education classes. The data collected points, especially, to issues related to the initial education and its implication in the way of dealing with this subject in school. It was stood out the neglect with the teaching of dance among the subjects in physical education. It reinforces the necessity of extend and deepen the discussions so that dance becomes really effectual in school.

Keywords: Dancing. Physical Education. Education, primary.
\end{abstract}

Educación Física Escolar y Danza: percepciones
de profesores en la enseñanza primaria
Resumen: Este artículo presenta datos y discusiones
de una investigación cuyo objetivo fue comprender la
percepción de profesores de educación física en la
enseñanza primaria, en relación al contenido danza
en las clases de educación física. Los datos recaba-
dos apuntan, especialmente, para cuestiones relacio-
nadas a la formación inicial y sus implicaciones en el
trato con ese contenido en la escuela. Se destacó la
negligencia con la enseñanza de la danza entre los
contenidos de la educación física, lo que refuerza la
necesidad de ampliar y profundizar las discusiones a
fin de visualizar un camino para que la enseñanza de
la danza realmente sea efectiva en el ámbito escolar.
Palabras claves: Baile. Educación Física. Educación
primaria.

\section{REFERÊNCIAS}

ARNOV, Mike. Ensinando dança através dos esportes. Revista Dançar, s/d.

BOND, Karen. Como "criaturas selvagens" domaram as distinções de gênero. Proposições, Campinas, v. 9, n. 2, jun., 1998.

BRASILEIRO, Lívia Tenório. O conteúdo "dança" em aulas de Educação Física: temos o que ensinar? Pensar a Prática, Goiânia, v. 6, n.1, p.45-58, 2003.

. O conhecimento no currículo escolar: o conteúdo dança em aulas de educação física na perspectiva crítica. Movimento, Porto Alegre, v. 8, n. 3, p.5-18, set./ dez., 2002.

Movimento, Porto Alegre, v. 15, n. 04, p. 193-214, outubro/dezembro de 2009. 
BURT, Ramsay. The male dancer: bodies, spectable, sexualities. London: Routledge, 1995.

ESCOBAR, Micheli O. Cultura corporal na escola: tarefas da educação física. Motrivivência, Florianópolis, dez., 1999.

FIAMONCINI, Luciana; SARAIVA, Maria do Carmo. Dança na escola: a criação e a coeducação em pauta. In: KUNZ, Elenor (Org.). Didática da educação física. ljuí: UNIJUİ, 1998.

FRAGA, Alex Branco. Concepções de gênero nas praticas corporais de Adolescentes. Movimento, Porto Alegre, v. 2, n. 3, 1995.

FREIRE, Paulo. Pedagogia da autonomia: saberes necessários à prática educativa. 12. ed. São Paulo: Paz e Terra, 1996.

HANNA, Judith. Dança, sexo e gênero: signos de identidade, dominação, desafio e desejo. Tradução de Mauro Gama. Rio de Janeiro: Rocco, 1999.

KUNZ, Elenor. A imprescindível necessidade pedagógica do professor: o método de ensino. Motrivivência, Florianópolis, v. 9, n. 13, p.63-81, nov., 1999.

KUNZ, Elenor (Org). Didática da educação física I. ljuí: UNIJUI, 1998.

Didática da educação física II. ljuí: UNIJUI, 2001.

KUNZ, Elenor; TREBELS, Andreas H. (Org.). Educação física crítico-emancipatória: com uma perspectiva da pedagogia alemã do esporte. ljuí: UNIJUÍ, 2006.

LEITÃO, Fatima C. do V.; SOUSA, Iracema S. O homem que dança... Motrivivência, Florianópolis, v. 7, n. 8, p.250-259, dez., 1995.

LÜDKE, Menga; ANDRÉ, Marli. Pesquisa em educação: abordagens qualitativas. São Paulo: EPU, 1986.

MARQUES, Isabel. Ensino de dança hoje: textos e contextos. 2 ed. São Paulo: Cortez, 2001.

Dançando na escola. 2. ed. São Paulo: Cortez, 2005.

NANNI, Dionísia. Dança-educação: princípios, métodos e técnicas. Rio de Janeiro: Sprint, 1995.

PÉREZ GÓMEZ, Angel. Compreender o ensino na escola: modelos metodológicos de investigação educativa. In: SACRISTÀN, José Gimeno; PÉREZ GÓMEZ, Ángel. Compreender e transformar o ensino. 4. ed. Porto Alegre: Artmed, 1998.

SARAIVA, Maria do Carmo. Dança e gênero na escola: formas de ser e viver mediadas pela educação estética. 2003. Tese (Doutorado) - Faculdade do Movimento Humano, Universidade Técnica de Lisboa, Lisboa, 2003.

. O sentido da dança: arte, símbolo, experiência vivida e representação. Movimento, Porto Alegre, v. 11, n. 3, p.219-241, set./dez., 2005.

Movimento, Porto Alegre, v. 15, n. 04, p. 193-214, outubro/dezembro de 2009. 


\section{ArtigorOrigimais Neusa D. Kleinubing e Maria C. Saraiva}

SARAIVA, Maria do Carmo et al. Dança e seus elementos constituintes: uma experiência contemporânea. In: SILVA, Ana Márcia; DAMIANI, lara Regina (Org.). Práticas corporais, Florianópolis, v. 3, p.115-133, 2005a.

.Ensinar e aprender em dança: evocando as "relações" em uma experiência contemporânea. In: SILVA, Ana Márcia; DAMIANI, lara Regina (Org.). Práticas corporais, Florianópolis, v. 2, p.61-78, 2005b.

. Alguns significados e contextos na análise da dança numa pesquisa-ação. In: FALCÃO, José Luiz; SARAIVA, Maria do Carmo (Org.). Esporte e lazer na cidade: a prática teorizada e a teoria praticada. v. 2. Florianópolis: Lagoa, 2007a.

. Vivências em dança. Compreendendo as relações entre dança, lazer e formação. In: FALCÃO, José Luiz; SARAIVA, Maria do Carmo (Org.). Esporte e lazer na cidade: a prática teorizada e a teoria praticada. v. 1. Florianópolis: Lagoa, 2007b.

SILVA, Ana Márcia; DAMIANI, lara Regina. As práticas corporais em foco: a análise da experiência em questão. In: SILVA, Ana Márcia; DAMIANI, lara Regina (Org.). Práticas corporais. v. 3. Florianópolis: Nauemblu Ciência e Arte, p.187-207, 2005.

SOARES, Andresa et al. Improvisação e dança, conteúdos para a dança na educação física. Florianópolis: UFSC, 1998.

SOARES, Andresa; SARAIVA, Maria do Carmo. Fundamentos teórico-metodológicos para a dança na Educação Física. Motrivivência, Florianópolis, v. 9, n. 13, nov., 1999.

STINSON, Susan. Reflexões sobre a dança e os meninos. Pro-posições, Campinas, v. 9, n. 2, p.55-61, jun., 1998a.

Vozes de meninos adolescentes. Pro-posições, Campinas, v. 9, n. 2,

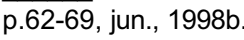

Recebido em: 09.06.2008

Aprovado em: 17.07.2009

Movimento, Porto Alegre, v. 15, n. 04, p. 193-214, outubro/dezembro de 2009. 